\title{
Microbiota bacteriana aeróbia da conjuntiva de doadores de córnea
}

\author{
Aerobic bacterial microbiota of the conjunctiva of cornea donors
}

\author{
Paula Fontana Lorenzini ${ }^{1}$ \\ Simone Ulrich Picoli ${ }^{2}$
}

Trabalho realizado no Centro Universitário Feevale Laboratório de Biomedicina - Novo Hamburgo (RS) Brasil.

${ }^{1}$ Biomédica pelo Centro Universitário Feevale - Novo Hamburgo (RS) - Brasil.

${ }^{2}$ Professora do Centro Universitário Feevale - Novo Hamburgo (RS) - Brasil.

Endereço para correspondência: Simone Ulrich Picoli. RS 239, n 2755 - Centro Universitário Feevale, Laboratório de Biomedicina - Novo Hamburgo (RS) CEP 933520-000

E-mail: simonepi@terra.com.br

Recebido para publicação em 21.07.2006

Última versão recebida em 10.11.2006

Aprovação em 24.11.2006

Nota Editorial: Depois de concluída a análise do artigo sob sigilo editorial e com a anuência do Dr. Élcio Hideo Sato sobre a divulgação de seu nome como revisor, agradecemos sua participação neste processo.

\begin{tabular}{l} 
RESUMO \\
\hline Objetivos: Determinar a microbiota bacteriana aeróbia da conjuntiva de \\
doadores de córnea e seu padrão de suscetibilidade a antibióticos; \\
verificar o número de córneas utilizadas para transplante e a média de \\
tempo de preservação em solução preservante com gentamicina e estrep- \\
tomicina; traçar o perfil dos doadores e receptores de córnea. Métodos: \\
Espécimes clínicos foram colhidos de saco inferior da conjuntiva de \\
ambos os olhos, de 40 doadores de córnea. As amostras foram inoculadas \\
emágar sangue azida, ágar chocolate égar MacConkey e o antibiograma \\
foi realizado pelo método de Kirby-Bauer. Resultados: A frequiência de \\
cultura positiva da conjuntiva de doadores de córnea foi de 72,5\%, sendo \\
que Gram-positivos totalizaram $81,6 \%$ e apenas $18,4 \%$ das amostras \\
foram identificadas como Gram-negativos. Vancomicina inibiu 100\% dos \\
Gram-positivos, ao passo que a sensibilidade dos Gram-negativos à \\
gentamicina foi de $53,8 \%$ e à estreptomicina foi de $30 \%$ O sexo masculino \\
predominou entre os doadores e receptores, a média de tempo entre o \\
óbito e a enucleação foi de $2 \mathrm{~h}$ e a de preservação em solução preservante \\
com gentamicina e estreptomicina foi de 7 dias. Neoplasia e mais de uma \\
causa associada foram as causas de óbito mais freqüentes. O ceratocone \\
foi a principal indicação para transplante (51,7\%). Conclusões: Staphy- \\
lococcus coagulase negativo foi o microrganismo com o maior número de \\
isolamentos, apresentando sensibilidade variada aos antimicrobianos. A \\
quantidade de córneas utilizadas para transplante foi bastante inferior em \\
relação ao total de captações. O perfil dos doadores e receptores de córnea \\
mostrou-se heterogêneo para grande parte das variáveis analisadas. \\
\hline
\end{tabular}

Descritores: Conjuntiva/microbiologia; Endoftalmite; Transplante de córnea; Doadores de tecidos; Testes de sensibilidade microbiana

\section{INTRODUÇÃ̃O}

O transplante de córnea constitui uma alternativa terapêutica cada vez melhor para grande parte das doenças corneanas ${ }^{(1)}$. No Brasil e no mundo, os avanços científicos, tecnológicos, organizacionais e administrativos têm colaborado para o aumento expressivo do número de transplantes. Contudo, esses dados animadores são limitados pelo volume insuficiente de doações ${ }^{(2-3)}$.

De acordo com a Associação Pan-Americana de Banco de Olhos (APABO), em 2004, existiam 130.000 pessoas à espera de um transplante de córnea na América Latina, e somente 16.400 foram realizados. No Brasil, neste mesmo período, 25.000 pessoas estavam incluídas na lista de espera para transplante de córnea, sendo realizados apenas 8.400 transplantes. A 
escassez de órgãos doados parece ser um reflexo da desinformação da população e da classe médica, além dos problemas estruturais do sistema de saúde, que tem se mostrado pouco competente no processo de captação de órgãos.

A superfície ocular é colonizada por microbiota bacteriana que contribui com a modulação de sua defesa, associada a fatores humorais próprios da sua superfície, inibindo o aparecimento de microrganismos patogênicos ${ }^{(4)}$. A conjuntiva, em especial, tem uma microbiota residente que consiste predominantemente em Staphylococcus coagulase negativo (SCN), Streptococcus do grupo viridans, Corynebacterium sp. e Propionibacterium acnes ${ }^{(5)}$. O isolamento de microrganismos da microbiota endógena, geralmente considerados de pouca virulência, alerta para o fato de que estes não podem ser desprezados automaticamente como contaminantes. Ao contrário, falhas ao excluir a microbiota normal durante os procedimentos de análise da amostra clínica podem levar à necessidade de maior tempo para a análise ou ao fornecimento de dados inacurados ao clínico ${ }^{(6)}$.

Com potencial destrutivo para os componentes estruturais do olho, a endoftalmite bacteriana é doença grave e sua causa está relacionada à entrada de agentes infecciosos após procedimentos cirúrgicos intra-oculares e ferimentos decorrentes de traumatismos penetrantes ${ }^{(7-8)}$. As bactérias são o grupo mais comum de agentes causativos de endoftalmites e patógenos Gram-positivos são responsáveis por 60 a $80 \%$ das infecções agudas, sendo SCN o microrganismo mais comumente isolado ${ }^{(9)}$. Num estudo de 55 casos de endoftalmite pós-transplante de córnea, 44 foram de origem bacteriana com cultura comprovada; destes, o mesmo microrganismo foi isolado do receptor e doador em $56,8 \%{ }^{(10)}$ dos casos.

As taxas de resistência aos antibióticos estão crescendo com a disseminação e uso prolongado de agentes antimicrobianos. Baseado nisto, a caracterização da microbiota bacteriana ocular e seu padrão de suscetibilidade são altamente justificados $^{(11)}$, principalmente para detectar tendências de resistência microbiana aos antibióticos presentes nos diferentes meios de preservação da córnea. Um estudo revelou que $64 \%$ dos Bancos de Olhos brasileiros usam solução preservante com gentamicina e estreptomicina ${ }^{(12)}$. Estes antibióticos fazem parte do grupo dos aminoglicosídeos, cujo mecanismo de ação é por meio da ligação ao ribossomo da bactéria, inibindo a síntese de proteínas. Os aminoglicosídeos são usados, primordialmente, para tratar infecções causadas por bacilos Gram-negativos aeróbicos ou em combinações sinérgicas com agentes antimicrobianos ativos na parede celular contra algumas bactérias Gram-positivas ${ }^{(13)}$.

Considerando a alta frequiência registrada de cultura positiva de material ocular ${ }^{(14-15)}$, este estudo teve por objetivos: (1) determinar a microbiota bacteriana aeróbia da conjuntiva de doadores de córnea do Banco de Olhos do Hospital Geral de Caxias do Sul e seu padrão de suscetibilidade a antibióticos; (2) verificar o número de córneas utilizadas para transplante e a média de tempo de preservação das mesmas em solução pre- servante com gentamicina e estreptomicina; (3) traçar o perfil dos doadores (sexo, idade, causa do óbito, tempo entre o óbito e a enucleação, resultados dos testes sorológicos) e receptores (sexo, idade e indicação para transplante) de córnea.

\section{MÉTODOS}

Realizou-se um estudo de determinação da microbiota conjuntival de 40 doadores de córnea do Banco de Olhos do Hospital Geral de Caxias do Sul, RS. Espécimes clínicos foram colhidos de saco inferior da conjuntiva de ambos os olhos, com o uso de "swab" estéril, antes da aplicação de qualquer antibiótico prévio ou irrigação do globo ocular com solução salina, e foi utilizado polivinilpirrolidona-iodo a $10 \%$ para assepsia da região periocular e pálpebras. Para transporte, foi utilizado meio de Stuart.

Todas as amostras foram inoculadas em ágar sangue azida, ágar chocolate e ágar MacConkey, cultivadas à $35 \pm 2{ }^{\circ} \mathrm{C}$ e observadas diariamente por um período de $48 \mathrm{~h}$. Cada colônia morfologicamente distinta foi corada pelo Gram.

As bactérias Gram-negativas foram identificadas pelos seguintes métodos: fermentação do ágar tríplice-açúcar (TSI); produção de urease; fenilalanina desaminase; inoculação em meio MIO (Motilidade, Indol, Ornitina); LIA (Lisina, Indol, Arginina); SIM (Produção de $\mathrm{H}_{2} \mathrm{~S}$, Indol, Motilidade); capacidade de multiplicação em citrato de Simmon's e teste da oxidase. Já as bactérias Gram-positivas foram submetidas à prova da catalase; prova da coagulase em tubo; hidrólise da esculina; inoculação em meio SIM (Produção de $\mathrm{H}_{2} \mathrm{~S}$, Indol, Motilidade); produção de urease e fermentação do ágar trípliceaçúcar (TSI).

A suscetibilidade aos antimicrobianos foi determinada para todas as culturas positivas usando o método de discodifusão de Kirby-Bauer. O inóculo foi preparado através de solução salina, comparando sua turvação com 0,5 da escala de McFarland e em seguida, este foi inoculado através de "swab" estéril na superfície do ágar Müeller Hinton. Após 18 a 24 horas de incubação, a leitura foi realizada medindo o diâmetro da zona de inibição de crescimento ao redor dos discos, de acordo com os critérios do "Clinical and Laboratory Standards Institute" (CLSI) em três categorias: resistente, intermediário ou sensível. Os discos antibióticos testados incluíram: amicacina $(30 \mu \mathrm{g})$, aztreonam $(30 \mu \mathrm{g})$, ceftazidima $(30 \mu \mathrm{g})$, cefalotina $(30 \mu \mathrm{g})$, cefoxitina $(30 \mu \mathrm{g})$, ciprofloxacina $(5 \mu \mathrm{g})$, clindamicina $(2 \mu \mathrm{g})$, cloranfenicol $(30 \mu \mathrm{g})$, estreptomicina $(10 \mu \mathrm{g})$, gentamicina $(10 \mu \mathrm{g})$, imipenen $(10 \mu \mathrm{g})$, oxacilina $(1 \mu \mathrm{g})$, rifampicina $(5 \mu \mathrm{g})$, sulfametoxazol-trimetoprim $(25 \mu \mathrm{g})$, tetraciclina $(30 \mu \mathrm{g})$, tobramicina $(10 \mu \mathrm{g})$ e vancomicina $(30 \mu \mathrm{g})$.

Informações sobre os doadores e os receptores foram obtidas de registros do Banco de Olhos do Hospital Geral de Caxias do Sul. Os dados coletados sobre os doadores foram idade, sexo, causa do óbito, tempo entre o óbito e a enucleação e resultados dos testes sorológicos (Anti-HCV, Anti-HIV, HBsAg, Anti-HBc total). Já para os receptores das córneas, os 
dados foram idade, sexo e indicação para o transplante. Número de córneas utilizadas para transplante e a média de tempo de preservação em solução preservante com gentamicina e estreptomicina também foram analisados neste estudo.

O estudo teve aprovação do Comitê de Ética em Pesquisa do Centro Universitário Feevale (processo 2.12.03.06.249), instituição aonde foi realizada a análise laboratorial.

\section{RESULTADOS}

Dos 40 doadores que participaram deste estudo, 12 (30\%) eram do sexo feminino e 28 ( $70 \%)$ do sexo masculino. A idade média destes doadores foi de 62,6 anos (mínima de 16 e máxima de 78 anos), a média de tempo entre o óbito e a enucleação foi de 2 horas, com amplitude de variação de 40 minutos a 4,6 horas e o tempo médio de preservação das córneas em solução preservante com gentamicina e estreptomicina foi de 7 dias (mínimo de 1 e máximo de 14 dias).

As causas do óbito estão apresentadas no gráfico 1 . Observa-se que as causas mais freqüentes foram a neoplasia e mais de uma causa associada (trauma vascular e parada cardiorrespiratória; aneurisma abdominal e parada cardiorrespiratória; neoplasia abdominal e ascite metastática; neoplasia de útero e parada cardiorrespiratória; insuficiência renal aguda e broncopneumonia; insuficiência renal aguda e falência de órgãos; neoplasia de ovário e insuficiência ventilatória; neoplasia de intestino e parada cardiorrespiratória; neoplasia de estômago e falência de órgãos; insuficiência renal aguda e traumatismo de crânio; neoplasia cerebral e insuficiência respiratória).

De acordo com os resultados dos testes sorológicos, 29 $(72,5 \%)$ doadores apresentaram resultado não reagente para anti-HCV, anti-HIV, anti-HBc total e HBsAg, enquanto que 11 $(27,5 \%)$ doadores apresentaram resultado reagente para um ou mais marcadores testados. Destes 11 doadores, $9(81,8 \%)$ apresentaram anticorpos anti-HBc total.

Após avaliação em lâmpada de fenda dos globos oculares e das córneas preservadas em solução com gentamicina e

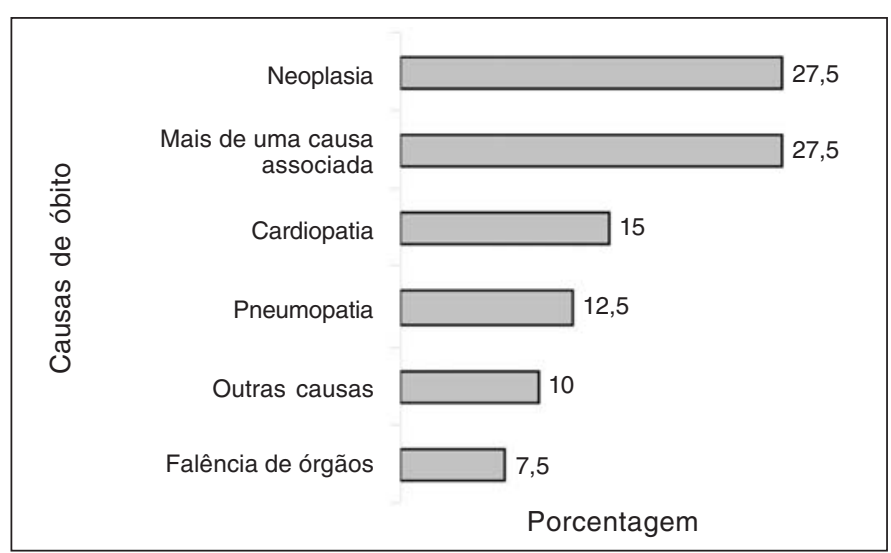

Gráfico 1 - Freqüência das causas de óbito dos doadores de córnea do Banco de Olhos do Hospital Geral estreptomicina, verificou-se que 29 tecidos doadores não se mostraram adequados para uso em transplante, levando-se em consideração a presença das seguintes características: exposição epitelial, defeito epitelial, opacidade subepitelial, edema estromal, estria estromal, infiltrado estromal, dobras na Membrana de Descemet, gutata, arco senil, pterígio, cicatrizes e reflexo especular.

Com relação à cultura, verificou-se crescimento bacteriano em $58(72,5 \%)$ das 80 amostras coletadas. Nessas, foram feitos 76 isolamentos de 10 bactérias diferentes. Os Gram-positivos totalizaram $81,6 \%$, sendo identificados como SCN em $44,8 \%$ dos casos, seguido por Corynebacterium sp. (19,7\%), Staphylococcus aureus (15,8\%) e Bacillus sp. (1,3\%). Apenas 18,4\% das amostras foram identificadas como Gram-negativas, entre elas Enterobacter aerogenes (5,2\%), Escherichia coli (4\%), Klebsiella pneumoniae (4\%), Pseudomonas aerugionosa (2,6\%), Proteus mirabilis (1,3\%) e Moraxella catarrhalis (1,3\%).

$\mathrm{Na}$ avaliação do antibiograma, cada grupo de bactérias pertencentes à mesma espécie foi analisado separadamente. $\mathrm{A}$ porcentagem de sensibilidade das bactérias Gram-positivas e Gram-negativas aos antibióticos testados está apresentada nas tabelas 1 e 2 .

Quanto aos dados relativos aos receptores de córnea, dos 29 olhos transplantados, a prevalência foi do sexo masculino (62\%), com idade média de 38,3 anos. A principal indicação para transplante de córnea foi o ceratocone em 15 olhos $(51,7 \%)$, seguido de outras indicações para transplante em 10 olhos $(34,5 \%)$, compreendendo úlcera perfurada, afilamento corneano, descemetocele secundária, cicatriz corneana póstrauma e leucoma; e rejeição em 4 olhos (13,8\%).

\section{DISCUSS $\tilde{A} O$}

A freqüência de cultura positiva da conjuntiva de olhos de doadores foi elevada $(72,5 \%)$ e este dado pode ser atribuído ao fato de que as amostras foram coletadas antes da aplicação de qualquer antibiótico prévio ou irrigação do globo ocular com solução salina.

\begin{tabular}{|lcc|}
\hline \multicolumn{3}{|c|}{$\begin{array}{c}\text { Tabela 1. Sensibilidade dos cocos Gram-positivos isolados da } \\
\text { conjuntiva de doadores de córnea }\end{array}$} \\
& $\begin{array}{r}\text { SCN } \\
\text { N (\%) }\end{array}$ & $\begin{array}{c}\text { S. aureus } \\
\text { N }(\%)\end{array}$ \\
Ciprofloxacina & $21(72,4)$ & $5(62,5)$ \\
Clindamicina & $20(64,5)$ & $7(58,3)$ \\
Cloranfenicol & $26(92,8)$ & $10(100)$ \\
Estreptomicina & $7(78,0)$ & $3(50,0)$ \\
Gentamicina & $26(76,5)$ & $9(75,0)$ \\
Oxacilina & $18(53,0)$ & $6(50,0)$ \\
Rifampicina & $27(82,0)$ & $9(75,0)$ \\
Sulfa+TMP* & $16(47,0)$ & $9(75,0)$ \\
Tetraciclina & $27(79,4)$ & $9(75,0)$ \\
Vancomicina & $34(100)$ & $12(100)$ \\
SCN= Staphylococcus coagulase negativo; ${ }^{*}=$ Sulfametoxazol-trimetoprim \\
\hline
\end{tabular}




\begin{tabular}{|c|c|c|c|c|c|}
\hline & $\begin{array}{c}\text { E. aerogenes } \\
\mathrm{N}(\%)\end{array}$ & $\begin{array}{l}\text { E. coli } \\
\mathrm{N}(\%)\end{array}$ & $\begin{array}{c}\text { K. pneumoniae } \\
\text { N (\%) }\end{array}$ & $\begin{array}{l}\text { P. mirabilis } \\
\mathrm{N}(\%)\end{array}$ & $\begin{array}{c}\text { P. aeruginosa } \\
\mathrm{N}(\%)\end{array}$ \\
\hline Amicacina & $3(100 \%)$ & $3(100 \%)$ & $0(\quad 0 \%)$ & $1(100 \%)$ & $0(\quad 0 \%)$ \\
\hline Aztreonam & - & - & - & - & $1(50 \%)$ \\
\hline Ceftazidima & - & - & - & - & $2(100 \%)$ \\
\hline Cefalotina & - & $0(\quad 0 \%)$ & $0(0 \%)$ & $1(100 \%)$ & - \\
\hline Cefoxitina & - & $3(100 \%)$ & $2(66,7 \%)$ & $1(100 \%)$ & - \\
\hline Ciprofloxacina & $4(100 \%)$ & $3(100 \%)$ & $1(33,3 \%)$ & $1(100 \%)$ & $0(0 \%)$ \\
\hline Cloranfenicol & $4(100 \%)$ & - & $0(\quad 0 \%)$ & - & - \\
\hline Estreptomicina & $1(100 \%)$ & $0(\quad 0 \%)$ & $1(33,3 \%)$ & $1(100 \%)$ & $0(\quad 0 \%)$ \\
\hline Gentamicina & $4(100 \%)$ & $1(33,3 \%)$ & $1(33,3 \%)$ & $1(100 \%)$ & $0(0 \%)$ \\
\hline Imipenem & - & - & - & - & $2(100 \%)$ \\
\hline Sulfa+TMP* & $1(25 \%)$ & $1(33,3 \%)$ & $3(100 \%)$ & $1(100 \%)$ & - \\
\hline Tetraciclina & $1(25 \%)$ & $2(66,7 \%)$ & $1(33,3 \%)$ & $0(0 \%)$ & - \\
\hline Tobramicina & $4(100 \%)$ & $1(33,3 \%)$ & $1(33,3 \%)$ & $1(100 \%)$ & $0(0 \%)$ \\
\hline
\end{tabular}

Em contrapartida, algumas culturas não apresentaram crescimento bacteriano, como mostrado também em outros estudos ${ }^{(4,16)}$. Determinados fatores podem ter contribuído para este achado, incluindo quantidade insuficiente de amostra, uso de antibiótico pelo doador antes da realização do exame cultural, ou ainda, presença de microrganismos que necessitem de condições especiais para tal crescimento.

O presente estudo corrobora os achados da literatura no que se refere à alta frequiência de isolamentos de Gram-positivos, principalmente de SCN, microrganismo relacionado, aproximadamente, a $70 \%$ dos casos de endoftalmite pós-cirúrgica $^{(17)}$. Alguns autores observaram em amostras de "swabs" usadas para avaliação da microbiota da conjuntiva de pacientes submetidos à cirurgia oftalmológica, o crescimento entre $27 \%$ a $54 \%$ de $\mathrm{SCN}^{(18-19)}$.

A baixa frequiência de Gram-negativos, neste estudo, foi observada em outros trabalhos semelhantes, entretanto, com discordâncias em relação aos tipos bacterianos isolados. Para outros autores o Haemophilus sp. foi o Gram-negativo mais frequiente porém, não se isolou tal microrganismo neste estu$\mathrm{do}^{(16)}$. Paralelamente, Proteus mirabilis foi encontrado em poucas amostras oculares confrontando outros achados publicados $^{(20)}$.

Os resultados mostrados na tabela 1 revelam que a vancomicina teve a melhor atividade, inibindo a totalidade das bactérias Gram-positivas, resultado similar ao encontrado em outras pesquisas ${ }^{(18,20)}$.

Dados de um estudo recente indicaram que os SCN isolados apresentaram sensibilidade de apenas $2,6 \%$ ao cloranfenicol, enquanto $S$. aureus apresentou sensibilidade de $51,7 \%{ }^{(19)}$. A porcentagem de sensibilidade dessas bactérias em relação ao cloranfenicol foi notavelmente superior em nosso trabalho.

$\mathrm{O}$ alto grau de resistência apresentado por ambas espécies de Staphylococcus à oxacilina, não foi observado por outros autores. A literatura mostra a sensibilidade do $\mathrm{SCN}$ e do $S$. aureus de, aproximadamente, $85 \%$ e $100 \%$ respectivamente ${ }^{(18,20)}$.
Entre os Gram-negativos (Tabela 2), Enterobacter aerogenes predominou, exibindo ótima sensibilidade à tobramicina, cloranfenicol, gentamicina, amicacina, entre outros, e resistência importante ao sulfametoxazol-trimetoprim. O resultado do antibiograma se equivale ao descrito em trabalho semelhante exceto para o sulfametoxazol-trimetoprim, já que a sensibilidade encontrada pelo autor foi de $76 \%{ }^{(19)}$ frente a $25 \%$ no presente estudo.

Ceftazidima e imipenem foram os antibióticos mais eficazes em relação à Pseudomonas aeruginosa, isolada em 2,6\% das amostras. Por outro lado, esta bactéria apresentou resistência total a cinco antimicrobianos diferentes, incluindo a amicacina, em contraste ao descrito por um estudo precedente ${ }^{(19)}$, aonde o mesmo antibiótico foi o mais eficaz para Pseudomonas aeruginosa, com atividade biocida de $60 \%$. De um modo geral, os resultados encontrados sugerem a existência de bactérias multirresistentes colonizando a conjuntiva de doadores de córnea.

Apesar dos achados de Corynebacterium sp., Bacillus sp. e Moraxella catarrhalis, o antibiograma não foi realizado para estas bactérias devido à falta de padronização do teste pelo método de disco-difusão.

Considerando os antimicrobianos presentes na solução preservante de córneas, a sensibilidade apresentada à estreptomicina para bactérias Gram-positivas e negativas, foi, respectivamente, $66,6 \%$ e $30 \%$. Já para gentamicina a sensibilidade foi de $76 \%$ para os Gram-positivos e 53,8\% para os Gram-negativos. A sensibilidade insatisfatória demonstrada, em especial para os Gram-negativos, é preocupante, visto que estes dois antibióticos estão presentes na solução preservante de córneas mais utilizada pelos Bancos de Olhos. Neste viés, faz-se necessária uma reavaliação dos meios de preservação mais utilizados, com a possibilidade de adição de outros antimicrobianos, capazes de atingir o espectro não alcançado pelos já existentes.

Um outro ponto a ser considerado é o elevado número de córneas rejeitadas para uso em transplante. Nesta pesquisa, 
das 80 córneas captadas, 22 foram desprezadas devido aos resultados obtidos nos testes sorológicos e 29 apresentaramse inadequadas após análise morfológica através de lâmpada de fenda. Dessa maneira, a quantidade de córneas realmente destinada ao transplante foi, praticamente, três vezes menor em relação ao total de captações realizadas.

A preservação das 29 córneas utilizadas para transplante por um período médio de 7 dias, em solução preservante com gentamicina e estreptomicina, é considerada adequada, visto que o tempo prolongado de preservação (superior a 7 dias) provoca maior perda endotelial, o que pode diminuir a vida útil do transplante, apesar do fabricante assegurar a conservação viável da córnea, por um período de até 14 dias $^{(21-22)}$.

$\mathrm{O}$ ceratocone, doença que mais freqüentemente levou à indicação de transplante de córnea, correspondendo a 51,7\% dos casos, também foi a principal indicação relatada por outros trabalhos brasileiros ${ }^{(23-24)}$, porém com uma freqüência menor. Uma outra diferença observada é que a ceratopatia bolhosa não foi citada como indicação de transplante para nenhum dos 29 receptores de córnea envolvidos neste estudo, enquanto que nos outros trabalhos brasileiros citados anteriormente, esta doença foi a segunda indicação mais freqüente.

\section{CONCLUSÕES}

Com base nos resultados deste estudo, conclui-se que o SCN foi o microrganismo encontrado mais freqüentemente na conjuntiva de doadores de córnea, apresentando sensibilidade variada aos antimicrobianos.

A quantidade de córneas utilizadas para transplante foi bastante inferior em relação ao total de captações, em decorrência do grande número de doadores com resultado reagente para os testes sorológicos realizados e dos problemas detectados nos tecidos doadores após análise morfológica em lâmpada de fenda.

O perfil dos doadores e receptores de córnea mostrou-se heterogêneo às variáveis analisadas, com exceção do sexo masculino que predominou para ambos e do resultado não reagente para os testes sorológicos realizados com os doadores.

\section{ABSTRACT}

Purpose: To determine aerobic bacterial microbiota of the conjunctiva of cornea donors and its patterns of susceptibility to antibiotics; verify the number of corneas used for transplant and the average time of preservation in solutions with gentamicin and streptomycin; trace the profile of donors and receptors of cornea. Methods: Clinical specimens were collected from the inferior bag of the conjunctiva of both eyes of 40 cornea donors. The samples were inoculated into acid blood, chocolate and MacConkey agars, and the antibiogram was performed by the Kirby-Bauer method. Results: The frequency of positive cultures of the conjunctiva of cornea donors was $72.5 \%$, with Gram-positive totalling $81.6 \%$ and only $18.4 \%$ of the samples were identified as Gram-negative. Vancomycin inhibited $100 \%$ of Gram-positive microorganisms, while sensitivity of the Gram-negative to gentamicin was $53.8 \%$ and to streptomycin $30 \%$. Most donors and recipients were men, the average time between death and enucleation was approximately 2 hours and preservation in solution with gentamicin and streptomycin was around 7 days. Neoplasms and more than one associated cause were the most frequently causes of death. Keratoconus was the main indication for transplant (51.7\%). Conclusions: Coagulase-negative Staphylococcus was the most frequently isolated microorganism, presenting variable sensitivity to antimicrobians. The amount of corneas used for transplant was below the number of available corneas. Donor and receptor profiles were very heterogeneous regarding most of the analyzed variables.

Keywords: Conjunctiva/microbiology; Endophthalmitis; Corneal transplantation; Tissue donors; Microbial sensitivity tests

\section{REFERÊNCIAS}

1. Farge EJ, Silverman ML, Khan MM, Wilhelmus KR. The impact of state legislation on eye banking. Arch Ophthalmol. 1994;112(2):180-5.

2. Associação Brasileira de Transplantes de Órgãos. Latin American Transplantation Report. São Paulo (SP): ABTO; 2003.

3. Rodrigues AM, Sato E. Entendimento dos médicos intensivistas sobre o processo de doação de córneas. Arq Bras Oftalmol. 2003;66(1):29-32.

4. Uesugui E, Cypel-Gomes MC, Atique D, Goulart DG, Gallucci FR, Nishiwaki-Dantas MC, et al. Laboratory identification of the most frequent ocular pathogens and their in vitro sensitivity to antibiotics. Arq Bras Oftalmol. 2002;65(3):339-42.

5. Oplustil CP, Zoccoli CM, Tobouti NR, Sinto SI. Procedimentos básicos em Microbiologia clínica. São Paulo: Sarvier; 2000.

6. Souza CAI, Carcelli SE. Agressão por microorganismos da microbiota endógena. Arq Inst Biol. 2000;67:275-81.

7. Ng EW, Samiy N, Ruoff KL, Cousins FV, Hooper DQ, Von Gunten S, et al. Treatment of experimental Staphylococcus epidermidis endophthalmitis with oral trovafloxacin. Am J Ophthalmol. 1998;126(2):278-87.

8. Meredith TA, Aguilar HE, Miller MJ, Gardner SK, Trabelsi A, Wilson LA. Comparative treatment of experimental Staphylococcus epidermidis endophthalmitis. Arch Ophthalmol. 1990;108(6):857-60.

9. Ciulla TA, Starr MB, Masket S. Bacterial endophthalmitis prophylaxis for cataract surgery: an evidence-based update. Ophthalmology. 2002;109(1):13-24.

10. Kloess PM, Stulting RD, Waring GO 3rd, Wilson LA. Bacterial and fungal endophthalmitis after penetrating keratoplasty. Am J Ophthalmol. 1993;115 (3):309-16. Erratum in: Am J Ophthalmol. 1993;115(4):548.

11. Ta CN, Chang RT, Singh K, Egbert PR, Shriver EM, Blumenkranz MS, et al. Antibiotic resistance patterns of ocular bacterial flora: a prospective study of patients undergoing anterior segment surgery. Ophthalmology. 2003;110(10): 1946-51.

12. Pereira MLM, Santos AMC, Passos MC, Pecego JG. Análise comparativa entre os bancos de olhos brasileiros: da preservação à distribuição da córnea doada. Rev Bras Oftalmol. 2002;61(3):169-72.

13. American National Standards Institute. CLSI: Clinical and Laboratory Standards Institute. Performance Standards for Antimicrobial Disk Susceptibility Tests; Approved Standard. 8th ed. Washington, DC: American National Standards Institute; 2006.

14. Wang AG, Wu CC, Liu JH. Bacterial corneal ulcer: a multivariate study. Ophthalmologica. 1998;212(2):126-32.

15. Schirmbeck T, Romão E, Rodrigues MLV, Figueiredo JFC. Endoftalmite: análise de 58 casos. Arq Bras Oftalmol. 2000;63(1):39-44.

16. Höfling-Lima AL, Moeller CTA, Yu MCZ, Branco BC, Farah ME. Microbiological efficacy of lomefloxacin and other drugs regarding microorganisms isolated from the human conjunctiva. Arq Bras Oftalmol. 2001;64(2):147-51. 
17. Han DP, Wisniewski SR, Wilson LA, Barza M, Vine AK, Doft BH, et al Spectrum and susceptibilities of microbiologic isolates in the Endophthalmitis Vitrectomy Study. Am J Ophthalmol. 1996;122(1):1-17. Erratum in: Am J Ophthalmol. 1996;122(6):920.

18. Arantes TEF, Cavalcanti RF, Diniz MFA, Severo MS, Lins Neto J, Castro CMMB. Conjunctival bacterial flora and antibiotic resistance pattern in patients undergoing cataract surgery. Arq Bras Oftalmol. 2006;69(1):33-6.

19. Araújo MEXS, Scarpi MJ. Microbiota bacteriana da conjuntiva de doadores de córnea. Arq Bras Oftalmol. 2004;67(6):927-33.

20. Locatelli CI, Kwitko S, Simonetti AB. Conjunctival endogenous microbiota in patients submitted to cataract surgery. Braz J Microbiol. 2003;34(3):203-9.
21. Ghanem VC, Isaac DLC, Nascimento MA, Castro RS, Kara-José N. Eficácia na utilização de córneas no transplante penetrante. Arq Bras Oftalmol. 2003;66(3): 311-4.

22. Canals M, Costa J. Técnicas de conservación corneal. Annals d'Oftalmol. 1995;5(1):20-31.

23. Cattani S, Kwitko S, Kroeff MAH, Marinho D, Rymer S, Bocaccio FL. Indicações de transplante de córnea no Hospital de Clínicas de Porto Alegre. Arq Bras Oftalmol. 2002;65(1):95-8.

24. Fabris C, Corrêa ZMS, Marcon AS, Castro TN, Marcon IM, Pawlowski C. Estudo retrospectivo dos transplantes penetrantes de córnea da Santa Casa de Porto Alegre. Arq Bras Oftalmol. 2001;64(5):449-53.

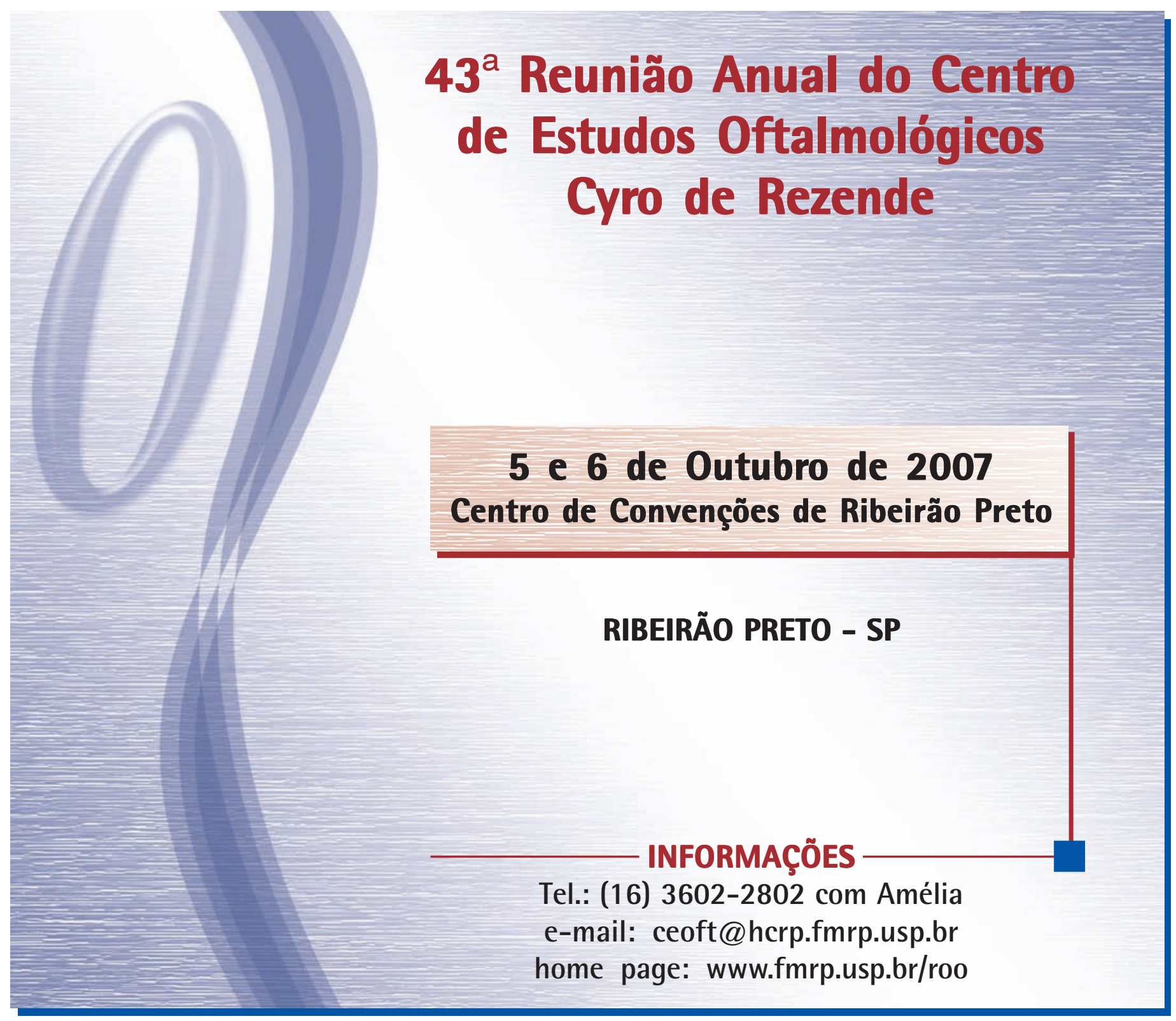

